\title{
Training inhibitory control. A recipe for resisting sweet temptations
}

Citation for published version (APA):

Houben, K., \& Jansen, A. (2011). Training inhibitory control. A recipe for resisting sweet temptations. Appetite, 56(2), 345-349. https://doi.org/10.1016/j.appet.2010.12.017

Document status and date:

Published: 01/01/2011

DOI:

10.1016/j.appet.2010.12.017

Document Version:

Publisher's PDF, also known as Version of record

Document license:

Taverne

Please check the document version of this publication:

- A submitted manuscript is the version of the article upon submission and before peer-review. There can be important differences between the submitted version and the official published version of record.

People interested in the research are advised to contact the author for the final version of the publication, or visit the DOI to the publisher's website.

- The final author version and the galley proof are versions of the publication after peer review.

- The final published version features the final layout of the paper including the volume, issue and page numbers.

Link to publication

\footnotetext{
General rights rights.

- You may freely distribute the URL identifying the publication in the public portal. please follow below link for the End User Agreement:

www.umlib.nl/taverne-license

Take down policy

If you believe that this document breaches copyright please contact us at:

repository@maastrichtuniversity.nl

providing details and we will investigate your claim.
}

Copyright and moral rights for the publications made accessible in the public portal are retained by the authors and/or other copyright owners and it is a condition of accessing publications that users recognise and abide by the legal requirements associated with these

- Users may download and print one copy of any publication from the public portal for the purpose of private study or research.

- You may not further distribute the material or use it for any profit-making activity or commercial gain

If the publication is distributed under the terms of Article $25 \mathrm{fa}$ of the Dutch Copyright Act, indicated by the "Taverne" license above, 


\title{
Training inhibitory control. A recipe for resisting sweet temptations ${ }^{\text {h }}$
}

\author{
Katrijn Houben *, Anita Jansen \\ Maastricht University, The Netherlands
}

\section{A R T I C L E I N F O}

\section{Article history:}

Received 2 August 2010

Received in revised form 10 December 2010

Accepted 20 December 2010

Available online 24 December 2010

\section{Keywords:}

Food

Restrained eating

Dieting

Response inhibition

Go/no-go task

\begin{abstract}
A B S T R A C T
When inhibitory control is lacking, people are more prone to indulge in high calorie food. This research examined whether training to inhibit food-related responses renders one less susceptible to temptations of high calorie food. Trait chocolate lovers were divided into three conditions: participants either consistently inhibited responding to chocolate stimuli (chocolate/no-go condition), consistently responded to chocolate stimuli (chocolate/go condition), or responded to chocolate stimuli only during half the trials (control condition). Chocolate consumption was measured following the manipulation with a taste test. Chocolate consumption did not differ between the control condition and the chocolate/ go condition, and increased as a function of dietary restraint in both conditions. In the chocolate/no-go condition, however, chocolate consumption was significantly reduced, and higher levels of dietary restraint were associated with decreased chocolate intake. These findings demonstrate that repeatedly practicing inhibitory control over food-related responses can help people regain control over the consumption of high calorie food.
\end{abstract}

(c) 2010 Elsevier Ltd. All rights reserved.

\section{Introduction}

In Western societies, where palatable, high calorie food is abundantly available, the prevalence of overweight and obesity is constantly increasing (Flegal, 2005; Wang \& Beydoun, 2007). As a result, more and more people attempt to control their weight through dieting. However, maintaining a successful diet is notoriously difficult, and only few dieters are able to reduce their body weight in the long term (Jeffery et al., 2000; Mann et al., 2007). This is especially true for the so-called restrained eaters, who chronically try to restrict their food intake, but who are mostly unsuccessful in their dieting attempts (Heatherton, Herman, Polivy, King, \& McGree, 1988; Herman \& Polivy, 1980) and who are more prone to overeating than unrestrained eaters (Fedoroff, Polivy, \& Herman, 1997; Jansen \& Van den Hout, 1991; Rogers \& Hill, 1989). Thus, people in general, and restrained eaters in particular, are often tempted by their impulses to indulge in tasty, high calorie food, even though this behaviour is inconsistent with their weight control goals. What makes it so difficult to resist the temptations of high calorie food?

According to contemporary dual-process models, like the Reflective-Impulsive model (Strack \& Deutsch, 2004), the outcome of such conflicts between the impulse to indulge in high calorie food and dieting standards critically depends on inhibitory control. Specifically, impulses can be overruled by higher order control

\footnotetext{
This research was supported by a grant from the Technology Foundation STW. * Corresponding author.

E-mail address: K.Houben@maastrichtuniversity.nl (K. Houben).
}

processes, but only when one is able to expend enough inhibitory control resources. Indeed, research has shown that people with weaker inhibitory control eat more high calorie, palatable food (Guerrieri, Nederkoorn, Schrooten, Martijn, \& Jansen, 2009; Guerrieri et al., 2007), are more often unsuccessful dieters (Jansen et al., 2009), and are more often overweight or obese (Guerrieri, Nederkoorn, \& Jansen, 2008; Nederkoorn, Braet, Van Eijs, Tanghe, \& Jansen, 2006; Nederkoorn, Guerrieri, Havermans, Roefs, \& Jansen, 2009; Nederkoorn, Jansen, Mulkens, \& Jansen, 2007) than people with more effective inhibitory control. Further, inhibitory control also interacts with dietary restraint, in such a way that especially restrained eaters are likely to overeat when they are low in inhibitory control (Jansen et al., 2009), and that food intake is more strongly related to automatic impulses and less strongly guided by dietary restraint standards when inhibitory control abilities are weak (Friese, Hofmann, \& Wänke, 2008; Hofmann \& Friese, 2008; Hofmann, Friese, \& Roefs, 2009; Hofmann, Rauch, \& Gawronski, 2007; Nederkoorn, Houben, Hofmann, Roefs, \& Jansen, 2010).

Hence, people need to recruit inhibitory capacity to override impulsive reactions to consume high calorie food. When this inhibitory capacity is insufficient, people are more susceptible to the temptations of tasty high caloric food, and they are more prone to indulge in these types of food. The present research examines whether the converse is also true: increasing inhibitory control should strengthen control over food intake, making people less vulnerable to the temptations of high calorie food and better able to restrict food intake in line with dietary standards. There is already some evidence suggesting that strengthening inhibitory control indeed decreases food consumption. Specifically, Guerrieri et al. (2009) demonstrated decreased food intake following a 
manipulation that primed inhibitory control compared to a manipulation that primed impulsive behaviour. However, in this study, there was no control condition, which makes it impossible to determine whether both the impulsivity and the inhibition manipulation effectively influenced food intake relative to baseline. Moreover, Guerrieri et al. primed general inhibition ability in their study and it is questionable whether such an endeavour will ultimately help people regain control over their food intake as they probably do not have a general problem inhibiting behaviour but a specific problem with resisting the temptation of palatable food.

In the present study, therefore, we examined whether practicing inhibition of food-related responses would reduce food intake relative to a control condition. In order to strengthen inhibitory control, we used a paradigm that involved repeatedly inhibiting (i.e., stopping) an approach response to stimuli. Importantly, stopping responses to stimuli in this paradigm has been demonstrated to involve motor inhibition (Veling \& Aarts, in press) and effectively increases response inhibition for those stimuli that were associated with a stopping response (Verbruggen \& Logan, 2008). Moreover, the same paradigm has been shown to decrease positive attitudes toward stimuli that were consistently associated with a stopping response (Houben, Nederkoorn, Wiers, \& Jansen, in press; Veling, Holland, \& van Knippenberg, 2008), and has even been demonstrated to facilitate behavioural changes (Houben et al., in press). Specifically, Houben et al. demonstrated that repeatedly inhibiting responses toward alcohol-related stimuli significantly reduced subsequent alcohol consumption. Based on these findings, the goal of this study was to test whether repeatedly inhibiting responses to high calorie food would decrease food intake.

Importantly, training to inhibit food-related responses should only affect eating behaviour for those experiencing strong impulses to indulge in certain types of food. Therefore, we selected a sample of trait chocolate cravers who experience intense and frequent cravings for chocolate (Benton, Greenfield, \& Morgan, 1998). Participants were randomly assigned to one of three conditions: in the control condition, participants were allowed to respond to chocolate on half the trials, while they had to inhibit their responses on the other half of the trials. In contrast, in the experimental chocolate/no-go condition, participants had to consistently inhibit their responses to chocolate. It was expected that strengthening inhibitory control toward chocolate in this way would decrease the consumption of chocolate during a subsequent taste test relative to the control condition. Further, it was expected that chocolate consumption would be more strongly guided by dietary restraint standards in the chocolate/no-go condition than in the control condition. Finally, we also included a chocolate/go condition, in which participants consistently had to respond to chocolate to examine whether such a manipulation would in fact increase impulsive chocolate consumption and would decrease dietary control over chocolate consumption.

\section{Method}

\section{Participants}

Sixty-nine female undergraduate students (age: $M=20.08$, $S D=2.25$ ) participated in this study. Participants were screened with the Attitudes to Chocolate Questionnaire (ACQ; Benton et al., 1998) 1-2 weeks before the study. The chocolate craving subscale of the ACQ consists of 10 items that measure the amount of chocolate craving with higher scores indicating stronger chocolate craving. Every item of the craving subscale presented a statement regarding the experience of craving for chocolate. Participants indicated on a 7-point Likert scale whether or not the statement matched their own feelings $(-3=$ not at all like me; $3=$ very much like me). Only high trait chocolate cravers, as indexed by a high score on the ACQ(i.e., a score above 10), were included in the study.

\section{Materials and measures}

\section{Go/no-go task}

The go/no-go task consisted of 2 blocks of 160 trials. During each block, participants were presented with pictures and were instructed to press the space bar when a go cue was displayed on the picture, and to refrain from responding when a no-go cue was displayed on the picture. The go/no-go cues were the letters ' $p$ ' and ' $\mathrm{f}$ ', which were displayed randomly in one of four corners of the pictures. Go/no-go instructions were counterbalanced. Picture stimuli were four pictures of chocolate snacks, four neutral pictures of empty plates, and 8 filler pictures (snack foods; e.g., crisps, nuts). Filler stimuli were used to mask the goal of the study and to avoid demand characteristics. Each trial simultaneously presented a picture and a go/no-go cue (1500 ms). Participants had to respond by pressing the space bar when the picture was accompanied by the go cue, but had to refrain from responding when the picture was accompanied by the no-go cue. A green circle was displayed after a correct (non)response $(500 \mathrm{~ms})$, and a red cross an after incorrect (non)response (500 ms).

Participants were randomly assigned to one of three conditions. In the control condition ( $n=22)$, all pictures were presented with the go cue during half the trials and with the no-go cue during the other half of the trials. In the chocolate/no-go condition $(n=24)$, chocolate-related pictures were consistently paired with the no-go cue, while pictures of empty plates were consistently paired with the go cue. The eight filler pictures were presented with the go cue on half the trials and with the no-go cue on the other half of the trails. In the chocolate/go condition $(n=23)$, chocolate-related pictures were always paired with the go cue, and pictures of empty plates were always paired with the no-go cue. The eight filler pictures were presented with the go cue on half the trials and with the no-go cue on the other half of the trails. In each condition, all stimuli were presented ten times in both blocks. Go and no-go trials were always presented in random order.

\section{Restraint Scale}

The Restraint Scale (RS; Herman \& Polivy, 1980) was used to measure the extent to which participants try to restrain their food intake. The RS is a self-report questionnaire consisting of 10 items assessing concern for dieting and weight fluctuations. The maximum score on this scale is 35 , while the minimum score is 0 . Higher scores indicate an increased intention to restrict food intake.

\section{Body Mass Index}

Participants' weight and height were assessed in order to calculate participants' Body Mass Index ( $\left.\mathrm{kg} / \mathrm{m}^{2} ; \mathrm{BMI}\right)$.

\section{Taste test}

Chocolate was measured using a bogus taste test. During the taste test, participants were presented three bowls, each containing $200 \mathrm{~g}$ of one of three types of chocolate pellets: milk chocolate (Callebout Select 823NV; 33.6\% cocoa), dark chocolate (Callebout Select $811 \mathrm{NV} ; 53.8 \%$ cocoa), and extra dark chocolate (Callebout Satongo CHD-L7243STGNV; $72.4 \%$ cocoa). Participants were instructed to consume as much or as little as they wished to judge the taste and texture of the different types of chocolates. After $10 \mathrm{~min}$, the experimenter removed the bowls of chocolate and the amount of chocolate consumed was measured outside the test room. 
Table 1

Mean age, BMI (Body Mass Index $=\mathrm{kg} / \mathrm{m}^{2}$ ), restraint, and chocolate consumption per condition (standard deviations within parentheses).

\begin{tabular}{|c|c|c|c|c|c|}
\hline & Control condition & Chocolate/go condition & Chocolate/no-go condition & $F$ & $p$ \\
\hline Age & $20.16(2.17)$ & $19.94(2.79)$ & $19.72(1.64)$ & $F(2,52)<1$ & .84 \\
\hline BMI & $22.56(4.05)$ & $21.14(2.32)$ & $23.46(3.79)$ & $F(2,60)=2.27$ & .11 \\
\hline RS & $17.14(10.71)$ & $12.69(8.00)$ & $18.76(10.77)$ & $F(2,58)=1.88$ & .16 \\
\hline Consumption & $28.72(15.66)$ & $22.62(9.51)$ & $17.07(10.96)$ & $F(2,60)=4.73$ & .01 \\
\hline
\end{tabular}

Note: Eight participants had missing data for age, and two participants had missing data on the Restraint Scale.

\section{Procedure}

Participants were deprived of food for $2 \mathrm{~h}$ before the start of the study. This was done to control for different states of hunger between the conditions at the start of the experiment. After giving consent, participants filled out the Restraint Scale, and we measured weight and length to calculate BMI. Next, participants were randomly assigned to the control condition, the chocolate/ no-go condition, or the chocolate/go condition, and performed the go/no-go task. After the go/no-go task, participants performed the taste test. Finally, we probed participants for awareness of the purpose of the critical go/no-go manipulation with open questions asking participants to report what they thought was the goal of the study and what they considered to be the goal of the go/no-go task. At the end of the study, all participants were thanked for their cooperation and received course credits or a gift certificate as remuneration for their participation.

\section{Results}

Four participants correctly guessed the goal of the go/no-go manipulation and were therefore removed from the sample. In addition, two outliers with a chocolate consumption that was 2.5 $S D$ above the mean chocolate consumption were also removed from the sample. The final sample consisted of 63 participants, divided over the go/no-go control condition $(n=22)$, the chocolate/ no-go condition $(n=21)$ and the chocolate/go condition $(n=20)$. There were no significant differences in age, BMI, or restraint between the three conditions (see Table 1 ).

The effect of the go/no-go manipulation on chocolate consumption was tested using ANOVA. Results demonstrated a significant effect of condition on chocolate consumption, $F(2$, $60)=4.73, p=.01$. Follow-up comparisons showed that partici-

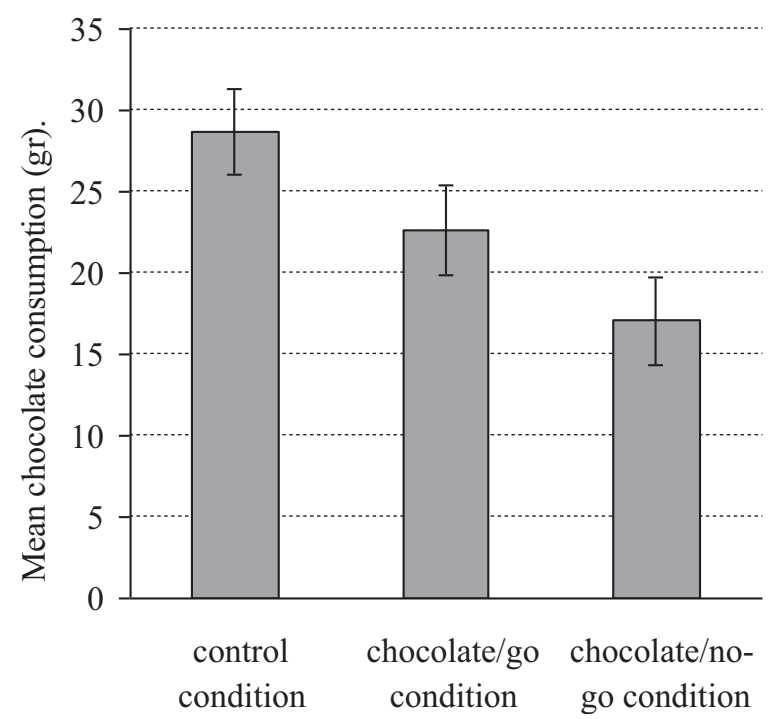

Fig. 1. Mean chocolate consumption, separately for the control condition, the chocolate/go condition, and the chocolate/no-go condition. pants in the chocolate/no-go condition consumed significantly less chocolate compared to the control condition, $t(60)=-3.07, p<.01$, while chocolate consumption in the chocolate/go condition did not differ significantly from consumption in either the control condition, $t(60)=-1.59, p=.12$, or the chocolate/no-go condition, $t(60)=1.43, p=.16$. Mean chocolate consumption in each condition is presented in Fig. 1. While restraint did not differ significantly between the three conditions, Table 1 shows that participants in the chocolate/no-go condition and the control condition met the cut-off for restrained eating (i.e., a score of 15 or higher), participants in the chocolate/go condition did not meet this criterion. Hence, the effect of condition on chocolate consumption may have been influenced by these differences in restraint.

To control for restraint differences between the three conditions, we performed a regression analysis controlling for restraint scores. In addition, we also tested whether the effect of the manipulation on chocolate consumption was moderated by restraint. In the regression analysis, we entered two dummies to test for the effect of condition on chocolate consumption, restraint (standardized), and the interaction terms between the condition dummies and restraint. Inspection of Cook's distances and standardized residuals showed no influential outliers (all Cook's distances $<1$; absolute value of all standardized residuals $<3$ ). The regression model, $R^{2}=.28, F(5,55)=4.27, p=.002$, showed a significant difference between the chocolate/no-go condition and the control condition in the prediction of chocolate consumption, $\beta=-.77, t(55)=-2.80, p<.01$, but not between the chocolate/go condition and the control condition, $\beta=-.28, t(55)<1$. In addition, restraint significantly predicted chocolate consumption,

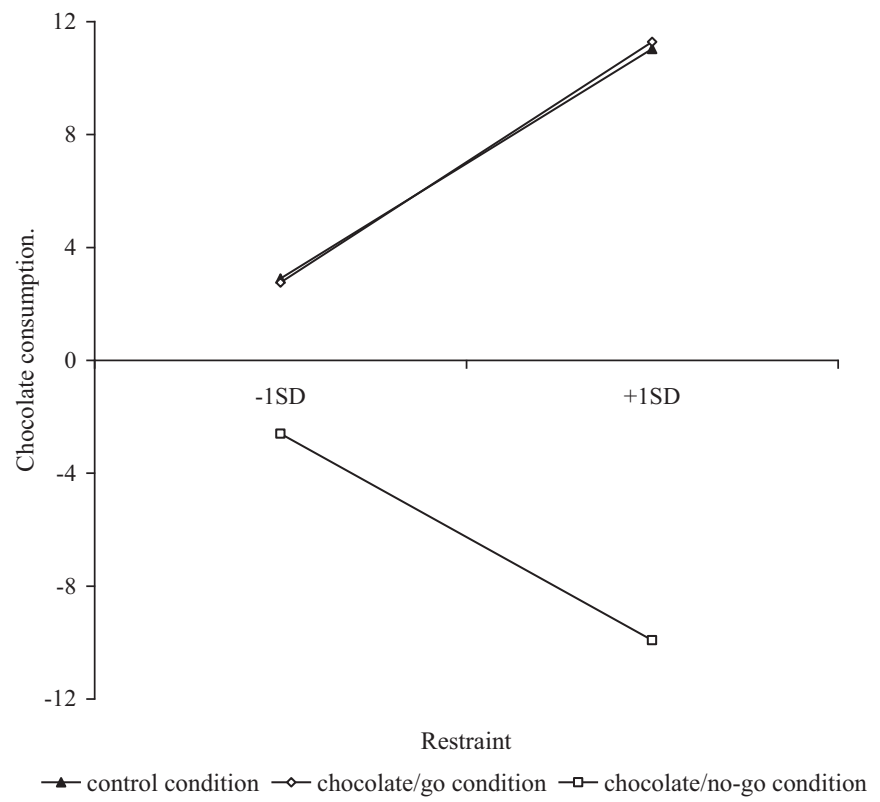

Fig. 2. A two-way interaction plot illustrating the simple slopes for the prediction of chocolate consumption (standardized estimate) by restraint, separately for the three go/no-go conditions. 
$\beta=.40, t(55)=2.17, p=.03$. These main effects of restraint and control versus chocolate/no-go were qualified by a significant interaction effect, $\beta=-.76, t(55)=-2.89, p<.01$, indicating that the prediction of chocolate consumption by restraint differed significantly between the control condition and the chocolate/nogo condition. In contrast, the prediction of chocolate consumption by restraint did not differ between the control condition and the chocolate/go condition, as evidenced by a non-significant interaction effect, $\beta=.02, t(55)<1$.

Simple slopes for the prediction of chocolate consumption by restraint in each condition are shown in Fig. 2. Tests of the simple slopes demonstrated that chocolate consumption increased significantly as a function of restraint in the control condition, $\beta=.40, t(55)=2.17, p=.03$. In the chocolate/go condition, the simple slope failed to reach significance, $\beta=.42, t(55)=1.52$, $p=.13$, although it was in the same direction as in the control condition. In the chocolate/no-go condition, in contrast, there was a trend indicating that chocolate consumption decreased as a function of restraint, $\beta=-.36, t(55)=-1.92, p=.06$.

\section{Discussion}

The present study examined whether training inhibition of food-related responses effectively increases control over food intake so that consumption of high calorie food is more in line with dietary restraint standards. Specifically, as a first attempt to test this hypothesis, the inhibition training aimed to increase control over chocolate consumption in a sample of trait chocolate cravers. As expected, participants who consistently had to inhibit their responses to chocolate stimuli in the chocolate/no-go condition consumed significantly less chocolate relative to the control condition where participants were allowed to respond to chocolate on half the trials. In contrast, chocolate consumption did not differ significantly between participants who consistently responded to chocolate in the chocolate/go condition and participants in the control condition. Finally, consumption also did not differ significantly between the chocolate/no-go condition and the chocolate/go condition.

Thus, while it was expected that the chocolate/go condition would show even higher levels of consumption than the control condition, the present findings showed no difference in chocolate consumption between the control condition and the chocolate/go condition. When controlling for baseline differences in restraint between the chocolate/go condition and the control condition in the regression analysis, we also found no difference in consumption between these two conditions. Further, the difference in consumption between the control condition and the chocolate/go condition was also not influenced by restraint, indicating that higher levels of dietary restraint were related to increased chocolate consumption in both conditions. This finding is consistent with other research demonstrating that restrained eaters are more prone to overeating than unrestrained eaters (Fedoroff et al., 1997; Jansen \& Van den Hout, 1991; Rogers \& Hill, 1989), especially when they are low in inhibitory control (Jansen et al., 2009). Hence, participants who had to impulsively respond to chocolate did not show higher levels of consumption compared to control. A possible explanation for this finding is that trait chocolate cravers already experience high cravings for chocolate (Benton et al., 1998), resulting in impulsive chocolate consumption, so that training them to become even more impulsive with respect to chocolate is almost impossible due to a ceiling effect. Alternatively, the impulsivity manipulation may have been too weak to further increase impulsivity toward chocolate in the present sample of chocolate cravers.

Consistent with our predictions, consumption in the chocolate/ no-go condition was significantly decreased relative to consump- tion in the control condition, also when controlling for differences in restraint. Moreover, strengthening inhibitory control over chocolate-related responses reversed the relationship between restraint and consumption, so that higher levels of dietary restraint predicted decreased chocolate intake in the chocolate/no-go condition. These findings are in line with dual-process models stating that stronger inhibitory control is related to better control over food intake (Strack \& Deutsch, 2004). Further, while previous research already demonstrated that decreasing inhibitory capacity results in weaker dietary control over food intake (Friese et al., 2008; Hofmann \& Friese, 2008; Hofmann et al., 2007), the present findings demonstrate that increasing inhibitory control strengthens dietary control over consumption. Finally, we also performed a regression analysis with different dummy coding to further examine the contrast between the chocolate/go condition and the chocolate/no-go condition, when controlling for restraint. This analysis also yielded a significant interaction with restraint, $\beta=.78, t(55)=2.34, p=.02$, indicating that higher levels of dietary restraint were associated with increased levels of consumption in the chocolate/go condition but with decreased consumption in the chocolate/no-go condition. Thus, differences in consumption between the chocolate/go condition and the chocolate/no-go condition became more pronounced with increased dietary restraint. Since restraint scores were higher in the chocolate/nogo condition compared to the chocolate/go condition, this finding explains why we were unable to find a significant difference in chocolate consumption between these two conditions when restraint was not taken into account.

Finally, it should be noted that the present study did not include a dependent measure of response inhibition, and therefore there is only indirect evidence suggesting that the go/no-go manipulation strengthened response inhibition for chocolate-related stimuli: first, previous research has already demonstrated that a similar manipulation effectively increased response inhibition for those stimuli associated with a stopping response (e.g., Veling \& Aarts, in press; Verbruggen \& Logan, 2008). Second, the effect of the manipulation in this study was moderated by dietary restraint suggesting that the manipulation successfully increased dietary control over eating behaviour. Nevertheless, it remains unclear whether increased inhibition of chocolate-related responses indeed mediated the effects of the manipulation on consumption. The reason for not including such a dependent measure of chocolate-related response inhibition is that performing such a task after the manipulation might decrease or even erase the effects of the manipulation on chocolate consumption. Therefore, the present study focused on the effects of the manipulation on consumption to test whether this procedure has any merit for strengthening control over eating behaviour. The present findings indeed show that this is the case. The next step for future research is to unequivocally establish that increased inhibition is the main mechanism underlying effects of the go/no-go manipulation on behaviour. In addition, previous research has also demonstrated that repeatedly inhibiting responses toward stimuli decreases evaluations of those stimuli (e.g., Houben et al., in press; Veling et al., 2008). Attitudes toward chocolate were not measured in the present study because this was not the primary focus. However, it would be interesting for future research to also include attitude measures to examine whether these also change as a result of the manipulation and how they contribute to observed changes in consumption.

In sum, the present findings indicate that training to inhibit food-related responses can be an effective strategy to help people regain control over eating behaviour, and decrease food intake. Importantly, the inhibition training proved especially effective for people who are already chronically trying to restrict food intake to maintain or achieve a healthy weight, but are generally unsuc- 
cessful at their dieting attempts. Although the inhibition training in this study specifically targeted inhibition for chocolate in a sample of chocolate cravers, the training is of course not limited to only this type of food. Future research should therefore further examine the effectiveness of the training with other types of energy dense food in order to develop a more comprehensive training program aimed at strengthening inhibition for high calorie food in general. Nevertheless, the present findings are a first step forward in this endeavour, demonstrating that inhibition training can be an efficient strategy to increase one's resilience to the temptations of tasty, high calorie food.

\section{References}

Benton, D., Greenfield, K., \& Morgan, M. (1998). The development of the attitudes to chocolate questionnaire. Personality and Individual Differences, 24, 513-520.

Fedoroff, I. C., Polivy, J., \& Herman, C. P. (1997). The effect of pre-exposure to food cues on the eating behaviour of restrained and unrestrained eaters. Appetite, 28, 33-47.

Flegal, K. M. (2005). Epidemiologic aspects of overweight and obesity in the United States. Physiology E Behavior, 86, 599-602.

Friese, M., Hofmann, W., \& Wänke, M. (2008). When impulses take over. Moderated predictive validity of explicit and implicit attitude measures in predicting food choice and consumption behaviour. British Journal of Social Psychology, 47, 397-419.

Guerrieri, R., Nederkoorn, C. \& Jansen, A. (2008). The interaction between impulsivity and a varied food environment. Its influence on food intake and overweight. International Journal of Obesity, 32, 708-714.

Guerrieri, R., Nederkoorn, C., Schrooten, M., Martijn, C., \& Jansen, A. (2009). Inducing impulsivity leads high and low restrained eaters into overeating, whereas current dieters stick to their diet. Appetite, 53, 93-100.

Guerrieri, R., Nederkoorn, C., Stankiewicz, K., Alberts, H., Geschwind, N., Martijn, C., et al. (2007). The influence of trait and induced state impulsivity on food intake in normal-weight healthy women. Appetite, 49, 66-73.

Heatherton, T. F., Herman, C. P., Polivy, J. P., King, G. A., \& McGree, S. T. (1988). The (mis)measurement of restraint. An analysis of conceptual and psychometric issues. Journal of Abnormal Psychology, 97, 19-28.

Herman, C. P., \& Polivy, J. P. (1980). Restrained eating. In A. J. Stunkard (Ed.), Obesity (pp. 208-225). Philadelphia: Saunders.

Hofmann, W., \& Friese, M. (2008). Impulses got the better of me. Alcohol moderates the influence of implicit attitudes toward food cues on eating behavior. Journal of Abnormal Psychology, 117, 420-427.

Hofmann, W., Friese, M., \& Roefs, A. (2009). Three ways to resist temptation. The independent contributions of executive attention, inhibitory control and affect regulation to the impulse control of eating behavior. Journal of Experimental Social psychology, 45, 431-435.
Hofmann, W., Rauch, W., \& Gawronski, B. (2007). And deplete us not into temptation. Automatic attitudes, dietary restraint, and self-regulatory resources as determinants of eating behavior. Journal of Experimental Social Psychology, 43, 497-504.

Houben, K., Nederkoorn, C., Wiers, R. W., \& Jansen, A. Resisting temptation. Decreasing alcohol-related affect and drinking behavior by training response inhibition. Drug and Alcohol Dependence, in press.

Jansen, A., \& Van den Hout, M. (1991). On being led into temptation. 'Counterregulation' of dieters after smelling a 'preload'. Addictive Behaviors, 5, 247-253.

Jansen, A., Nederkoorn, C., van Baak, L., Keirse, C., Guerrieri, R., \& Havermans, R. (2009). High-restrained eaters only overeat when they are also impulsive. Behaviour Research and Therapy, 47, 105-110.

Jeffery, R. W., Epstein, L. H., Wilson, G. T., Drewnowski, A., Stunkard, A. J., \& Wing, R. R. (2000). Long-term maintenance of weight loss. Current status. Health Psychology, 19, 5-16.

Mann, T., Tomiyama, A. J., Westling, E., Lew, A.-M., Samuels, B., \& Chatman, J. (2007). Medicare's search for effective obesity treatments. Diets are not the answer. American Psychologist, 62, 220-233.

Nederkoorn, C., Braet, C., Van Eijs, Y., Tanghe, A., \& Jansen, A. (2006). Why obese children cannot resist food. The role of impulsivity. Eating Behaviors, 7, 315322 .

Nederkoorn, C., Guerrieri, R., Havermans, R. C., Roefs, A., \& Jansen, A. (2009). The interactive effect of hunger and impulsivity on food intake and purchase in a virtual supermarket. International Journal of Obesity and Related Metabolic Disorders, 33, 905-912.

Nederkoorn, C., Houben, K., Hofmann, W., Roefs, A., \& Jansen, A. (2010). Control yourself or just eat what you like? Weight gain over a year is predicted by an interactive effect of response inhibition and implicit preference for snack foods. Health Psychology, 29, 389-393.

Nederkoorn, C., Jansen, E., Mulkens, S., \& Jansen, A. (2007). Impulsivity predicts treatment outcome in obese children. Behaviour Research and Therapy, 45, 1071-1075.

Rogers, P. J., \& Hill, A. J. (1989). Breakdown of dietary restraint following mere exposure to food stimuli. Interrelationship between restraint, hunger, salivation, and food intake. Addictive Behaviors, 14, 387-397.

Strack, F., \& Deutsch, R. (2004). Reflective and impulsive determinants of social behavior. Personality and Social Psychology Review, 8, 220-247.

Veling, H. \& Aarts, H. Unintentional preparation of motor impulses after incidental perception of need-rewarding objects. Cognition E Emotion, in press, doi:10.1080/ 02699931.2010 .524053$.

Veling, H., Holland, R. W., \& van Knippenberg, A. (2008). When approach motivation and behavioral inhibition collide. Behavior regulation through stimulus devaluation. Journal of Experimental Social Psychology, 44, 1013-1019.

Verbruggen, F., \& Logan, G. D. (2008). Automatic and controlled response inhibition. Associative learning in the Go/No-Go and Stop-Signal paradigms. Journal of Experimental Psychology. General, 137, 649-672.

Wang, Y., \& Beydoun, M. A. (2007). The obesity epidemic in the united states-gender, age, socieconomic, Racial/Ethnic, and geographic characteristics. A systematic review and meta-analysis. Epidemiologic Reviews, 29, 6-23. 